\title{
Histomorfometria e histoquímica dos ovários, tubas e útero de ratas hipotireóideas em metaestro-diestro
}

[Histomorphometry and histochemistry of the ovaries, oviduct and uterus in hypothyroid rats in the metaestrus-diestrus]

\section{C.M. Silva, R. Serakides, T.S. Oliveira, N.M. Ocarino, E.F. Nascimento, V.A. Nunes}

\author{
Escola de Veterinária da UFMG \\ Caixa Postal 567
}

30123-970 - Belo Horizonte, MG

\section{RESUMO}

A foliculogênese ovariana foi estudada em ratas adultas Wistar, hipotireóideas na fase de metaestrodiestro. O hipotireoidismo foi induzido pela administração oral e diária de propiltiouracil (1mg/animal). As ratas eutireóideas receberam placebo. Após 120 dias de tratamento, foi colhido o plasma para dosagem de tiroxina livre, progesterona e estradiol após o que foram sacrificadas para colheita dos ovários, tubas e útero, para avaliação histomorfométrica e histoquímica. $\mathrm{O}$ hipotireoidismo reduziu significativamente o peso dos ovários e o número de folículos secundários e terciários e de corpos lúteos sem, no entanto, alterar a porcentagem de folículos atrésicos e o número de folículos primários e pré-ovulatórios. As células da granulosa dos folículos secundários das ratas hipotireóideas apresentavam núcleo pequeno com significativa redução do número de regiões organizadoras de nucléolo (NORs). Essas mudanças não alteraram os valores periféricos de estradiol e de progesterona. Houve redução significativa da espessura do endométrio, do número de glândulas endometriais e da altura do epitélio do infundíbulo.

Palavras-chave: rata, hipotireoidismo, ovário, tuba, útero, NORs

\begin{abstract}
Ovarian folicullogenesis was studied in adult Wistar rats. The animals were hypothyroid in the metaestrus/diestrus phase of the estrous cycle. Hypothyroidism was induced by oral treatment with $1 m g / a n i m a l$ of propylthiouracil. Euthyroid rats were kept under the same experimental conditions receiving placebo. After 120 days under treatment, all animals were killed and plasma was taken to assessing free thyroxine, progesterone, and estradiol. The ovaries, tubes and uterus were sampled for histomorphometric and histochemistry evaluation. Hypothyroidism significantly reduced the weight of the ovaries and the number of secondary and tertiary follicles, and corpora luteum. The number of atretic follicles as well as primary and pre-ovulatory follicles was not affected. Granulosa cells in the secondary follicles of treated rats had small nuclei with a reduced number of AgNORs. Significant reduction of the endometrium thickness, number of endometrial glands and the infundibulum epithelium height was observed.
\end{abstract}

Keywords: rat, hypothyroidism, ovary, oviduct, uterus, NORs

Recebido para publicação em 2 de setembro de 2003

Recebido para publicação, após modificações, em 25 de junho de 2004

E-mail: serakide@dedalus.lcc.ufmg.br 


\section{INTRODUÇÃO}

A fertilidade da fêmea depende do desenvolvimento adequado das gônadas, da maturação do oócito, da proliferação e diferenciação das células da granulosa (Elvin e Matzuk, 1998) e da interação entre os fatores endócrinos, autócrinos e parácrinos que coordenam as alterações cíclicas do ovário durante a foliculogênese (Elvin e Matzuk, 1998).

Nos últimos anos foi comprovada a participação da tireóide no controle da função reprodutiva, tendo sido demonstrados alguns dos efeitos dos hormônios tireoidianos na foliculogênese e esteroidogênese ovarianas de ratas pré-púberes, promovendo a diferenciação das células da granulosa (Mattheij et al., 1995; Gregoraszczuk et al., 1999) e em fêmeas adultas, estimulando a ovulação (Maruo et al., 1992b; Serakides et al., 2001).

O hipotireoidismo é considerado importante causa de cistos ovarianos e de infertilidade na mulher e nas fêmeas de outras espécies. Além disso, na mulher, a deficiência dos hormônios tireoidianos causa irregularidade do ciclo menstrual, ciclos anovulatórios e polimenorréia (Krassas, 2000) ou amenorréia (Tamura et al., 1998). Em fêmeas gestantes, pode induzir ao aborto (Johnson, 1994) ou originar neonatos prematuros de baixo peso e com anomalias congênitas (Thomas e Reid, 1987; Krassas, 2000).

Apesar da influência comprovada dos hormônios tireoidianos na foliculogênese e esteroidogênese ovarianas, o mecanismo pelo qual as disfunções da tireóide alteram a função ovariana ainda não foi totalmente elucidado (Maruo et al., 1987; Dijkstra et al., 1996). A definição se a ação desses hormônios sobre o ovário é direta ou indireta ainda não foi obtida. Postula-se que a redução ou o aumento da secreção tireoidiana atue indiretamente sobre o ovário, alterando sua responsividade às gonadotropinas (Maruo et al., 1992b). No entanto, a presença de receptores para triiodotironina nas células da granulosa sugere também uma ação direta (Wakim et al., 1993; Wakim et al., 1994).

A maior parte dos efeitos do hipotireoidismo sobre o ovário foi elucidada a partir de pesquisas in vitro e em animais pré-púberes. Poucas informações estão disponíveis sobre as respostas do ovário ao hipotireoidismo em fêmeas púberes, e o resultado da deficiência dos hormônios da tireóide sobre a taxa de proliferação das células da granulosa também não é conhecido. Além disso, mesmo ocorrendo ovulação, a gestação nem sempre é levada a termo sob as baixas concentrações de hormônios tireoidianos (Balen e Kurtz, 1990). Haveria alguma modificação na tuba e no útero que prejudicaria a fertilização e a implantação do oócito? A morfologia uterina já foi estudada em animais hipotireóideos (Inuwa e Williams, 1996), mas não há registros de estudos sobre a morfologia da tuba uterina no hipotireoidismo.

Assim, estudar o efeito do hipotireoidismo na histomorfometria dos ovários, da tuba uterina e do útero de ratas adultas hipotireóideas é pertinente, complementar e se constituiu no objetivo deste trabalho.

\section{MATERIAL E MÉTODOS}

Foram utilizadas 12 ratas Wistar adultas com dois meses de idade, na fase de metaestrodiestro. As ratas foram alojadas em caixas plásticas, numa densidade de três ratas/caixa, recebendo ração comercial $(1,4 \%$ de cálcio, $0,6 \%$ de fósforo, $22 \%$ de proteína e micronutrientes em concentrações recomendadas), água destilada $a d$ libitum e eram mantidas em regime de 12 horas com luz e 12 horas sem luz e a uma temperatura de $25^{\circ} \mathrm{C}$.

Após um período de 30 dias de adaptação, as ratas foram separadas ao acaso em dois grupos, tratado e controle. No grupo tratado $(n=6)$, o hipotireoidismo foi induzido pela administração diária de propiltiouracil, por sonda oro-gástrica, na dose de $1 \mathrm{mg} /$ animal diluída em $5 \mathrm{ml}$ de água destilada. As ratas do grupo-controle $(n=6)$ foram mantidas no estado eutireóideo recebendo $5 \mathrm{ml}$ de água destilada como placebo.

Após 120 dias do início do tratamento, todas as ratas foram sacrificadas por punção cardíaca, quando foi colhido o sangue em tubos com heparina para obtenção do plasma, seguindo-se exame pós-morte detalhado. O plasma foi armazenado a $-20^{\circ} \mathrm{C}$ para dosagem posterior de tiroxina livre, progesterona e estradiol pela 
técnica de quimioluminescência ${ }^{1}$ em sistema totalmente automático, utilizando-se kit comercial e seguindo o protocolo recomendado pelo fabricante.

À necropsia os ovários foram colhidos, inspecionados e pesados separadamente em balança de precisão, sendo obtida a média das duas gônadas. Os ovários, tubas e úteros foram fixados em formalina a $10 \%$ neutra e tamponada e processados segundo a técnica rotineira de inclusão em parafina e corados pela técnica da hematoxilina e eosina. Os ovários foram submetidos à microtomia seriada com cortes de $4 \mu \mathrm{m}$ de espessura. A cada 20 secções histológicas foram selecionadas cinco de cada ovário, totalizando 10 secções/animal, que foram submetidas à análise morfológica e morfométrica. Na área total abrangida pela secção histológica, foi quantificada a porcentagem de folículos atrésicos, o número total de folículos em crescimento, o de folículos primários, secundários, terciários, préovulatórios e de corpos lúteos (Freeman, 1994). Para cada variável foi obtida a média das 10 secções.

A classificação histológica dos folículos ovarianos foi a preconizada por Freeman (1994). Para classificação das fases do ciclo estral foi adotado o critério preconizado por Bronson et al. (1975).

Também foi realizada a evidenciação e a quantificação das AgNORs mediante impregnação dos cortes histológicos de ovários pela prata segundo a técnica descrita por Ploton et al. (1986) e modificada por Aubele et al. (1994). Para a coloração foram utilizados uma mistura da solução aquosa de nitrato de prata a $50 \%$ com a solução de ácido fórmico a $1 \%$, contendo $2 \%$ de gelatina microbiológica incolor. A incubação foi feita em câmara úmida e escura a $37{ }^{\circ} \mathrm{C}$ por 20 minutos.

Em uma secção histológica do ovário (direito ou esquerdo) com objetiva de imersão, foram quantificadas as AgNORs em 60 núcleos das células da granulosa de folículos secundários com duas a três camadas de células e de folículos secundários com mais de cinco camadas de

${ }^{1}$ Acsess Immunoassay Sistem,Sanofi Diagnostics Pasteur Inc., Chaska, MN, USA. células da granulosa. Somente foram incluídas na contagem as AgNORs que se encontravam individualizadas como pontos pretos ou marrons. Quando se apresentavam agrupadas eram registradas como uma única AgNORs, conforme descrição da literatura (Crocker et al., 1989). Ao final, para os folículos secundários com duas a três camadas e para os folículos secundários com mais de cinco camadas foi obtida a média do número das AgNORs dos 60 núcleos.

Um corte histológico de cada segmento da tuba (istmo, ampola e infundíbulo) foi selecionado e submetido à coloração pela técnica de HE. A altura do epitélio de cada segmento da tuba, da base até o ápice, desprezando-se os cílios, foi medida em 30 pontos aleatórios com auxílio de uma ocular micrométrica ${ }^{2}$. Uma secção histológica do terço médio do corno uterino foi selecionada e submetida à coloração de HE. Foram tomadas quatro medidas da espessura da parede do útero e do miométrio e endométrio, em pontos eqüidistantes. Ao final, um fator de correção foi aplicado às médias, obtido pela escala de uma lâmina micrométrica. $\mathrm{O}$ número de glândulas endometriais presente em toda a área abrangida pela secção histológica também foi determinado.

Um corte histológico de cada segmento da tuba uterina foi selecionado e submetido às colorações pelo ácido periódico de Schiff (PAS) (Lison, 1960) e azul alciano (AB) em pH 2,5 (Mowry, 1956) para estudo de mucossubstâncias. A análise da secreção baseou-se na seguinte classificação: grau 1: secreção fraca na forma de grânulos no citoplasma das células com distribuição multifocal e ausente no lúmen; grau 2: secreção fraca coalescente presente no citoplasma e ápice das células, às vezes com extrusão para o lúmen; grau 3: secreção forte granular ou coalescente no citoplasma das células e no glicocálix e ausente no lúmen e grau 4: secreção forte granular ou coalescente no citoplasma das células, no glicocálix e no lúmen.

O útero também foi submetido à coloração pela técnica do PAS (Lison, 1960) para análise de sua secreção que baseou-se na seguinte classificação: grau 1: endométrio com epitélio PAS positivo e glândulas negativas; grau 2: endométrio com epitélio PAS positivo e glândulas com secreção

${ }^{2}$ Carl Zeiss, KPL-W 10x 
PAS positivas somente no citoplasma das células e grau 3: endométrio com epitélio PAS positivo e glândulas com secreção PAS positivas no citoplasma e no lúmen.

O delineamento experimental foi o inteiramente ao acaso, com dois tratamentos e seis repetições por tratamento, sendo cada animal uma repetição. As médias foram comparadas pelo teste $t$ de Student. Para análise da intensidade de secreção foi utilizado o teste não paramétrico de Mann-Whitney. Também foi verificada a correlação entre os valores de T4 livre e todas as variáveis estudadas (Sampaio, 1998).

\section{RESULTADOS E DISCUSSÃO}

Ao final do experimento os grupos (hipotireóideo e eutireóideo) eram compostos por ratas em diferentes fases do ciclo estral. Coincidentemente, em cada grupo, $71 \%$ das ratas estava na fase de metaestro-diestro e somente $29 \%$ estava no proestro-estro. A heterogeneidade dentro de cada grupo foi eliminada ao final do experimento com o descarte das ratas em proestro-estro que se encontravam em minoria e em número insuficiente para a análise. Esse critério foi adotado pois, à primeira vista, embora possa-se pensar que a sincronização de cio poderia minimizar a heterogeneidade das ratas no que se refere à fase do ciclo estral, sabe-se que as disfunções tireoidianas podem alterar a ciclicidade, prolongando ou encurtando as fases do ciclo estral (Matheij et al., 1995). Assim, mesmo sincronizando o ciclo das ratas, ao final do experimento ocorreria perda da ciclicidade induzida pelo hipotireoidismo.

As concentrações plasmáticas de T4 livre no grupo tratado (hipotireóideo) $(0,05 \pm 0,05 \mathrm{ng} / \mathrm{ml})$ foram significativamente menores do que as do grupo controle (eutireóideo) $(1,84 \pm 0,53 \mathrm{ng} / \mathrm{dl})$, o que confirma a indução do estado hipotireóideo pelo propiltiouracil administrado durante o período experimental.

À macroscopia, os ovários das ratas hipotireóideas eram menores do que os das ratas eutireóideas, o que foi confirmado pelo peso também significativamente menor nas ratas tratadas. Esse resultado não surpreende, pois a redução significativa do número de folículos secundários, terciários e de corpos lúteos, que representam a maioria dos componentes ovarianos, certamente resultaria em perda de massa tecidual e, conseqüentemente, redução do peso ovariano (Tab. 1).

Tabela 1. Média e desvio-padrão do peso e das variáveis histomorfométricas do ovário de ratas hipotireóideas e eutireóideas em metaestrodiestro

\begin{tabular}{lcc}
\hline \multirow{2}{*}{ Variável } & \multicolumn{2}{c}{ Grupo } \\
\cline { 2 - 3 } & Hipotireóideo & Eutireóideo \\
\hline Peso do ovário $(\mathrm{g})$ & $20,63 \pm 4,28 \mathrm{~b}$ & $33,42 \pm 6,60 \mathrm{a}$ \\
$\mathrm{N}^{\circ}$. de folículos não atrésicos & $5,72 \pm 1,73 \mathrm{~b}$ & $10,58 \pm 1,53 \mathrm{a}$ \\
$\mathrm{N}^{\mathrm{o}}$. de folículos primários & $3,23 \pm 1,01 \mathrm{a}$ & $3,35 \pm 1,09 \mathrm{a}$ \\
$\mathrm{N}^{\circ}$. de folículos secundários & $1,65 \pm 0,58 \mathrm{~b}$ & $4,25 \pm 0,95 \mathrm{a}$ \\
$\mathrm{N}^{\circ}$. de folículos terciários & $0,67 \pm 0,32 \mathrm{~b}$ & $3,03 \pm 0,97 \mathrm{~b}$ \\
$\mathrm{~N}^{\mathrm{o}}$. de folículos pré-ovulatórios & $0,02 \pm 0,04 \mathrm{a}$ & $0,12 \pm 0,15 \mathrm{a}$ \\
$\mathrm{N}^{\circ}$. de corpos lúteos & $4,50 \pm 1,07 \mathrm{~b}$ & $7,50 \pm 2,49 \mathrm{a}$ \\
Porcentagem de folículos atrésicos & $46,22 \pm 12,73 \mathrm{a}$ & $36,40 \pm 7,64 \mathrm{a}$ \\
\hline Médias seguidas de letras iguais na linha não diferem entre si \\
(P $\geq 0,05$ ).
\end{tabular}

Numa análise individual de cada uma das estruturas ovarianas nota-se que a deficiência de T4 livre não afetou os folículos primários, cujo número não diferiu em relação às ratas eutireóideas. Resultado semelhante também foi observado com a administração de tiroxina que não alterou significativamente $\mathrm{o}$ número $\mathrm{de}$ folículos primários (Serakides et al., 2001). Nesse mesmo estudo foi verificada correlação positiva entre a população de folículos primários e a concentração plasmática de T4 livre, sugerindo a participação dos hormônios tireoidianos no crescimento e na diferenciação dos folículos primordiais em ratas adultas. Não se observou correlação entre os valores de T4 livre e o número de folículos primários, mas vale ressaltar que o número de animais estudados foi três vezes menor do que o número de ratas utilizadas no experimento que comprovou a correlação significativa entre T4 e o número de folículos primários.

Os mecanismos que controlam a foliculogênese basal são pouco conhecidos (Baker e Spears, 1999; Gougeon e Busso, 2000). Embora o efeito das disfunções tireoidianas sobre a população de folículos primários seja contraditório, a ação dos hormônios tireoidianos na transição dos folículos primordiais não deve ser descartada e precisa ser elucidada, ainda que estejam envolvidos no crescimento folicular basal fatores autócrinos e parácrinos como o fator de células tronco (SFC), 
o fator de crescimento e a diferenciação nove (GDF-9), o EGF e o TGF- $\alpha$, e também as neurotrofinas, representadas pelo fator de crescimento neural (NGF) (Dissen et al., 1993), pelo fator neurotrófico derivado do cérebro (BDNF), pela neurotrofina-3 (NT-3) e pela NT-4 (Ojeda et al., 2000).

O efeito do hipotireoidismo na redução da foliculogênese ovariana ficou patente nos seus estádios mais tardios. Houve redução significativa da população de folículos secundários e terciários (Tab. 1) e correlação significativa entre a concentração plasmática de T4 livre e o número total de folículos não atrésicos, secundários e terciários (Tab. 2), o que aponta a participação dos hormônios tireoidianos no desenvolvimento folicular. Resultados semelhantes também já foram observados em fêmeas pré-púberes (Chan e Ng, 1995; Dijkstra et al., 1996).

Tabela 2. Coeficientes de correlação entre as variáveis estudadas e os valores plasmáticos de T4 livre em ratas hipotireóideas na fase de metaestro-diestro

\begin{tabular}{|c|c|}
\hline Variável & $\begin{array}{l}\text { Concentração plasmática } \\
\text { de T4 livre }\end{array}$ \\
\hline Peso do ovário & $0,88 * *$ \\
\hline $\mathrm{N}^{\mathrm{o}}$. de folículos em crescimento & $0,88 * *$ \\
\hline $\mathrm{N}^{\mathrm{o}}$. de folículos primários & $-0,05$ \\
\hline $\mathrm{N}^{\mathrm{o}}$. de folículos secundários & $0,93 * *$ \\
\hline $\mathrm{N}^{\mathrm{o}}$. de folículos terciários & $0,95 * *$ \\
\hline $\mathrm{N}^{\mathrm{o}}$. de folículo pré-ovulatórios & 0,29 \\
\hline $\mathrm{N}^{\mathrm{o}}$. de corpos lúteos & $0,77 *$ \\
\hline$\%$ de folículos atrésicos & $-0,41$ \\
\hline $\begin{array}{l}\mathrm{N}^{\mathrm{o}} \text { de regiões organizadoras de nucléolo (NORs) em folículos secundários com } 2 \text { a } 3 \\
\text { camadas de células da granulosa }\end{array}$ & $0,83 * *$ \\
\hline $\mathrm{N}^{\mathrm{o}}$ de NORs em folículos secundários com mais de 5 camadas de células da granulosa & $0,75^{*}$ \\
\hline Concentração plasmática de estradiol & 0,01 \\
\hline Concentração plasmática de progesterona & 0,12 \\
\hline
\end{tabular}

${ }^{*} \mathrm{P} \leq 0,05,{ }^{* *} \mathrm{P} \leq 0,001$.

As células da granulosa de folículos secundários com duas a três camadas de células da granulosa apresentam menor número de AgNORs quando comparadas às de folículos secundários com mais de cinco camadas de células, confirmando que essa técnica é boa para diferenciar o potencial proliferativo dessas células também em processos não neoplásicos (Silva et al., 2003). Além disso, resultados de pesquisas comprovaram correlação positiva entre o número de AgNORs e outros parâmetros da cinética celular que já estão bem estabelecidos como detectores da atividade proliferativa das células, tais como o MIB-1, o Ki-67, o PCNA e a incorporação de bromodeoxiuridina (BrdU) (Derenzini, 2000).

Sob o efeito do hipotireoidismo, o número de
AgNORs nas células da granulosa também foi menor nos folículos secundários com duas camadas de células em comparação àqueles com mais de cinco camadas de células (Tab. 3). Mas, os folículos secundários do ovário das ratas hipotireóideas, independente do estádio de desenvolvimento, apresentaram células da granulosa com núcleo pequeno e número significativamente menor de AgNOR, ao contrário dos ovários das ratas controle que apresentavam células da granulosa com núcleos grandes e com AgNORs em maior número e dispersas por todo o núcleo (Tab. 3; Fig. 1a a 1f). Outro fato que sugere a participação dos hormônios tireoidianos nas células da granulosa é a correlação altamente significativa e positiva entre o número de AgNORs e os valores de tiroxina livre (Tab. 2). 
Tabela 3. Média e desvio-padrão do número de regiões organizadoras de nucléolo (NORs) no núcleo das células da granulosa de folículos secundários nos ovários de ratas hipotireóideas e eutireóideas em metaestro-diestro

\begin{tabular}{|c|c|c|}
\hline \multirow{2}{*}{ Variável } & \multicolumn{2}{|c|}{ Grupo } \\
\hline & Hipotireóideo & Eutireóideo \\
\hline $\begin{array}{l}\mathrm{N}^{0} \text { de NORs no núcleo das células da granulosa de } \\
\text { folículos secundários com } 2 \text { a } 3 \text { camadas de células }\end{array}$ & $3,20 \pm 0,45 \mathrm{Bb}$ & $7,09 \pm 1,60 \mathrm{Ba}$ \\
\hline $\begin{array}{l}\mathrm{N}^{\mathrm{o}} \text { de NORs no núcleo das células da granulosa de } \\
\text { folículos secundários com mais de } 5 \text { camadas de células }\end{array}$ & $5,71 \pm 2,34 \mathrm{Ab}$ & $12,65 \pm 2,28 \mathrm{Aa}$ \\
\hline
\end{tabular}

Médias seguidas de letras minúsculas iguais na linha e maiúsculas iguais na coluna não diferem entre si $(\mathrm{P} \geq 0,05)$.

A participação dos hormônios tireoidianos na diferenciação e maturação das células da granulosa já foi estabelecida (Dijkstra et al., 1996). Como isso é um fator essencial ao desenvolvimento folicular, poder-se-ia afirmar que na deficiência dos hormônios tireoidianos a seqüência do desenvolvimento folicular é interrompida, já que ficou demonstrado no hipotireoidismo a redução da foliculogênese ovariana a partir dos folículos secundários (Tab. 1). Mas, nas ratas hipotireóideas adultas deste estudo, o número reduzido de AgNORs nas células da granulosa revela diminuição da atividade proliferativa dessas células. Djkstra et al. (1996) relataram que o hipotireoidismo altera a diferenciação e não modifica a proliferação das células da granulosa em ratas pré-púberes hipotireóideas. Como a proliferação e diferenciação das células da granulosa é essencial à esteroidogênese e conseqüente formação do antro folicular, característica dos folículos terciários (Priedkalns, 1982), a participação dos hormônios tireoidianos na proliferação das células da granulosa pode explicar o porquê da redução significativa também no número de folículos terciários.

Como seria esperado, com a redução do número de folículos secundários e terciários, o número de folículos pré-ovulatórios deveria ser menor nas ratas com hipotireoidismo, o que não ocorreu. Aliás, era raro encontrar folículos pré-ovulatórios nos ovários estudados. Esse resultado não surpreende visto que os folículos pré-ovulatórios não são evidenciados durante o metaestrodiestro. Mas, o número de corpos lúteos significativamente menor nas ratas hipotireóideas (Tab. 1) e a correlação positiva e altamente significativa entre T4 livre e o número de corpos lúteos (Tab. 2) sugerem ter ocorrido diminuição do número de folículos aptos a ovular. A diminuição da taxa de ovulação e de corpos lúteos também foi observada em ratas prépúberes hipotireóideas (Dijkstra et al., 1996). Esse efeito é exatamente o contrário do que já foi observado em ratas hipertireóideas, nas quais houve aumento da taxa de ovulação (Serakides et al., 2001) e aumento do número de fetos (Rosato et al., 1992).

Ainda que muitos estudos demonstrem os efeitos dos hormônios tireoidianos no ovário, até o momento não se sabe se a ação da T3 e T4 é direta ou indireta. Pesquisas in vitro demonstraram que a T3 exerce efeito modulatório na diferenciação das células da granulosa (Maruo et al., 1992a) e na esteroidogênese, sendo necessária a associação com o FSH. Contudo, a presença de receptores para T3 nas células da granulosa de diferentes espécies animais (Wakim et al., 1993; Dijkstra et al., 1996), assim como a proliferação das células da granulosa em resposta à estimulação por T3 sugerem a participação direta da tireóide na função ovariana (Wakim et al., 1993). Além disso, a correlação positiva e significativa das concentrações plasmáticas de T4 livre e o número total de folículos não atrésicos e de folículos secundários, terciários e pré-ovulatórios (Tab. 3) também sugere a participação direta dos hormônios tireoidianos no desenvolvimento folicular. Assim, pesquisas para elucidar os mecanismos pelos quais há redução da foliculogênese no hipotireoidismo são importantes. 

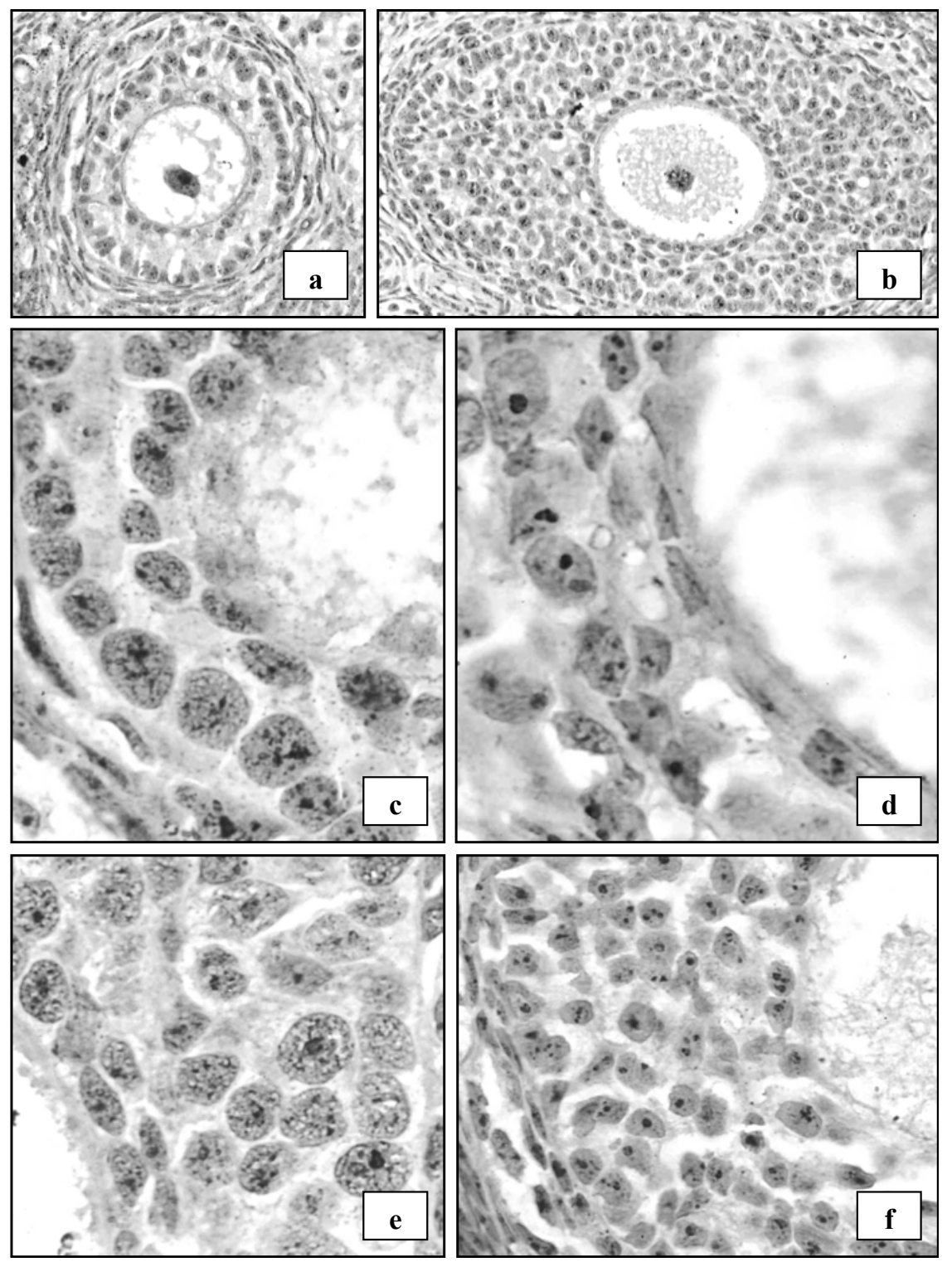

Figura 1. Ovário, rata adulta. a) Exemplar de folículo secundário com duas camadas de células da granulosa e oócito centrado utilizado na quantificação de regiões organizadoras de nucléolo argentafins (AgNORs), 125×. b) Exemplar de folículo com mais de cinco camadas de células da granulosa e oócito centrado utilizado na quantificação de AgNORs, 91,5×. c) Grupo eutireóideo (controle). Folículo secundário com duas camadas de células da granulosa apresentando AgNORs pequenas e em grande quantidade dispersas por todo o núcleo, 250×. d) Grupo hipotireóideo. Folículo secundário com duas camadas de células da granulosa apresentando AgNORs grandes e em pequeno número, 375×. e) Grupo controle. Folículo secundário com mais de cinco camadas de células da granulosa apresentando AgNORs de tamanhos variados e em grande quantidade dispersas por todo o núcleo número, 375×. f) Grupo hipotireóideo. Folículo secundário com mais de cinco camadas de células da granulosa apresentando AgNORs grandes e em pequeno número, $375 \times$. 
Sabe-se que os folículos não plenamente desenvolvidos entram em atresia (Chun e Hsueh, 1998). Embora tenha ocorrido aumento da porcentagem de folículos atrésicos no hipotireoidismo, a diferença entre grupos não foi significativa. Já com a indução do hipertireoidismo houve redução significativa do número de folículos atrésicos, no entanto semelhante ao observado no presente estudo não foi encontrada correlação significativa entre os valores de T4 e a taxa de atresia, sugerindo que a atresia folicular não seja um evento mediado pela ação direta dos hormônios tireoidianos (Serakides et al., 2001). Pesquisas in vitro demonstraram que a interação entre a $\mathrm{T} 3$ e os hormônios gonadotrópicos influencia a atresia folicular, inibe a produção excessiva de andrógenos pelas células da teca e estimula a aromatização, com produção de estrógeno pelas células da granulosa (Gregoraszczuk e Skalka, 1996). Contudo, a despeito da inibição da foliculogênese ovariana, o hipotireoidismo não alterou os valores periféricos de estrógeno e progesterona (Tab. 4).

Tabela 4. Média e desvio-padrão da concentração plasmática dos esteróides sexuais de ratas hipotireóideas e eutireóideas em metaestro-diestro

\begin{tabular}{lcc}
\hline \multirow{2}{*}{ Variável } & \multicolumn{2}{c}{ Grupo } \\
\cline { 2 - 3 } & Hipotireóideo & Eutireóideo \\
\hline Estradiol $(\mathrm{pg} / \mathrm{ml})$ & $31,83 \pm 11,14 \mathrm{a}$ & $33,50 \pm 7,97 \mathrm{a}$ \\
Progesterona $(\mathrm{pg} / \mathrm{ml})$ & $31110,96 \pm 18308,81 \mathrm{a}$ & $32458,43 \pm 11352,41 \mathrm{a}$ \\
\hline Médias seguidas de letras iguais na linha não diferem entre si $(\mathrm{P} \geq 0,05)$
\end{tabular}

Médias seguidas de letras iguais na linha não diferem entre si $(\mathrm{P} \geq 0,05)$.

A redução do número de folículos em crescimento (Tab. 1) não se apresenta acompanhada por alterações nas concentrações de estrógeno e progesterona, que não apresentaram diferença entre os grupos estudados (Tab. 4). Isso pode ter ocorrido pela variação nas concentrações desses hormônios entre as ratas do mesmo grupo, já que o coeficiente de variação das dosagens plasmáticas de estradiol e de progesterona está acima do ideal. Contudo, é preciso observar que a diminuição da foliculogênese não implica necessariamente em redução das concentrações periféricas dos hormônios sexuais, já que não houve correlação significativa entre o número de estruturas ovarianas quantificadas e os valores de estradiol e progesterona (dados não demonstrados). Talvez isso tenha ocorrido porque no hipotireodismo a atividade da globulina ligadora dos hormônios sexuais (HSBG) está diminuída, o que implica em aumento das frações livres de estrógeno plasmático (Ghosh et al., 1993). Dessa forma, para se obter resultados mais precisos da influência do hipotireoidismo sobre os valores plasmáticos de estrógeno e progesterona em cada fase do ciclo estral, seria importante avaliar as concentrações dos esteróides ovarianos a cada duas horas acompanhando todo o ciclo estral da rata que dura em média quatro dias (Freeman, 1994). Assim, seria possível verificar se os resultados obtidos em estudos in vitro que demonstram haver alteração da esteroidogênese folicular pelos hormônios da tireóide (Datta et al., 1998; Gregorasczuk et al., 1999) são compatíveis com os efeitos do hipotireoidismo in vivo.

Na tuba uterina, a deficiência dos hormônios tireoidianos reduziu o tamanho das vilosidades do infundíbulo, bem como o número e o tamanho das células de revestimento dos vilos e dos cílios, reduzindo significativamente a altura epitelial desse segmento (Tab. 5; Fig. 2 a e b). Apesar dessa alteração ter sido visualizada na fase de metaestro-diestro, cabe ressaltar que se a redução do epitélio do infundíbulo se repetisse na fase folicular do ciclo, fêmeas hipotireóideas, mesmo que ovulassem poderiam apresentar comprometimento da captação de oócitos, principal função do infundíbulo.

Tabela 5. Média e desvio-padrão da altura do epitélio $(\mu \mathrm{m})$ dos segmentos da tuba uterina de ratas hipotireóideas e eutireóideas em metaestrodiestro

\begin{tabular}{|c|c|c|c|}
\hline \multirow{2}{*}{ Grupo } & \multicolumn{3}{|c|}{ Segmento da tuba uterina } \\
\hline & Infundíbulo & Ampola & Istmo \\
\hline Eutireóideo & $8,7 \pm 0,78 \mathrm{Aa}$ & $9,8 \pm 1,9 \mathrm{Aa}$ & $10,5 \pm 2,0 \mathrm{Aa}$ \\
\hline Hipotireóideo & $7,05 \pm 0,82 \mathrm{Bb}$ & $9,9 \pm 1,34 \mathrm{Aa}$ & $9,24 \pm 1,4 \mathrm{Aa}$ \\
\hline
\end{tabular}




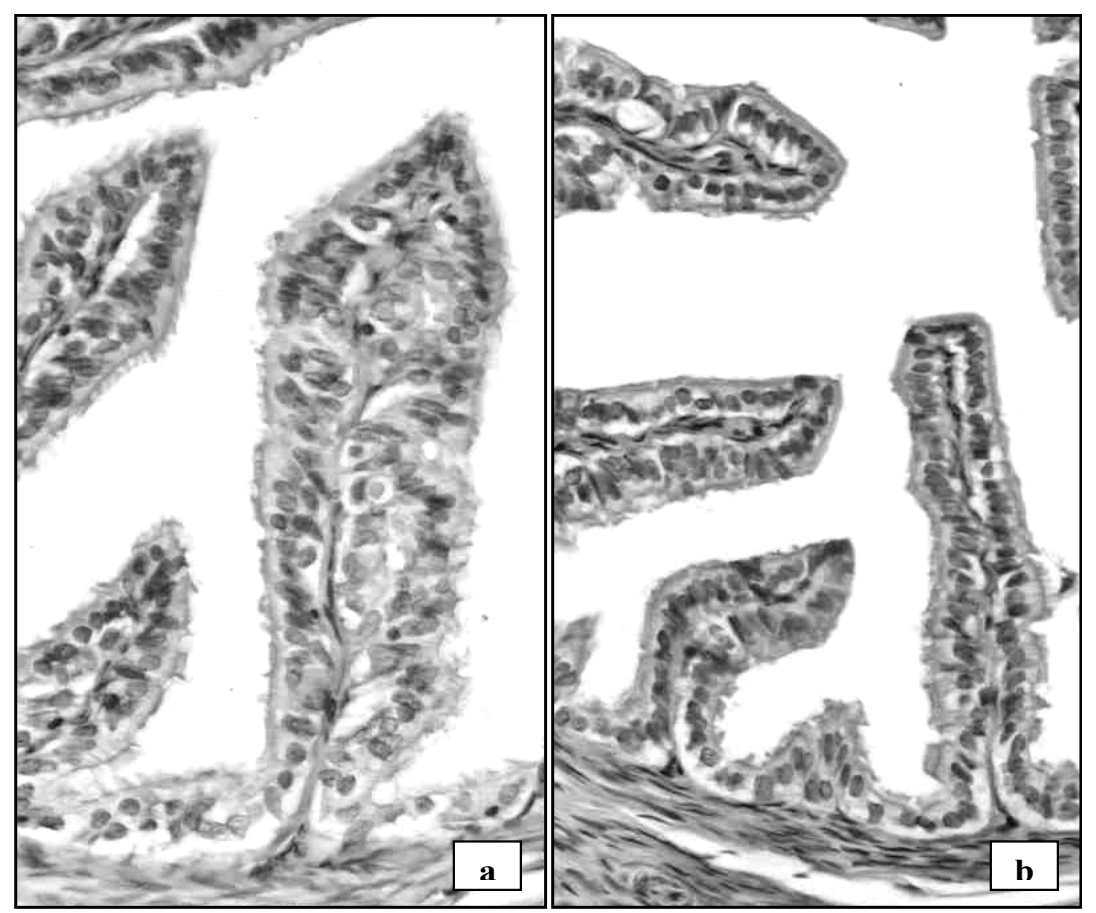

Figura 2. Tuba uterina, rata adulta. a) Grupo controle. Infundíbulo com vilosidades revestidas por epitélio alto, constituído por mais de uma camada de células volumosas e com grande quantidade de cílios. HE, $100 \times$ b) Grupo hipotireóideo. Infundíbulo com vilosidades revestidas por epitélio baixo constituído por uma única camada de células com pequena quantidade de cílios. HE, 100×.

O útero das ratas hipotireóideas apresentou diminuição significativa da espessura do endométrio e do número de glândulas endometriais, o que resultou em menor espessura de sua parede (Tab. 6; Fig. 3 a e b). Além disso, as glândulas endometriais apresentaram hipotrofia celular e redução intensa do lúmen em comparação ao grupo controle que apresentou endométrio espesso e com glândulas em maior número e contendo células volumosas (Fig. $3 \mathrm{c}$ e d). Resultados semelhantes foram descritos por Inuwa e Williams (1996). Todas essas alterações uterinas podem comprometer a implantação do zigoto, o que talvez explique o porquê de nem sempre a gestação, no hipotireoidismo, ser levada a termo.

Tabela 6. Média e desvio-padrão de todas as variáveis uterinas de ratas hipotireóideas e eutireóideas em metaestro-diestro

\begin{tabular}{lcc}
\hline Variável & \multicolumn{2}{c}{ Grupo } \\
\cline { 2 - 3 } & Eutireóideo & Hipotireóideo \\
\hline Número de glândulas endometriais & $65,86 \pm 20,09 \mathrm{~A}$ & $34 \pm 19,97 \mathrm{~B}$ \\
Espessura da parede do útero $(\mu \mathrm{m})$ & $850,00 \pm 160,00 \mathrm{~A}$ & $650,00 \pm 170,00 \mathrm{~B}$ \\
Espessura do endométrio $(\mu \mathrm{m})$ & $530,63 \pm 118,07 \mathrm{~A}$ & $340,98 \pm 82,08 \mathrm{~B}$ \\
Espessura do miométrio $(\mu \mathrm{m})$ & $298,91 \pm 35,74 \mathrm{~A}$ & $268,93 \pm 96,08 \mathrm{~A}$ \\
\hline
\end{tabular}

Médias seguidas de letras iguais na linha não diferem entre si $(\mathrm{P}>0,05)$. 

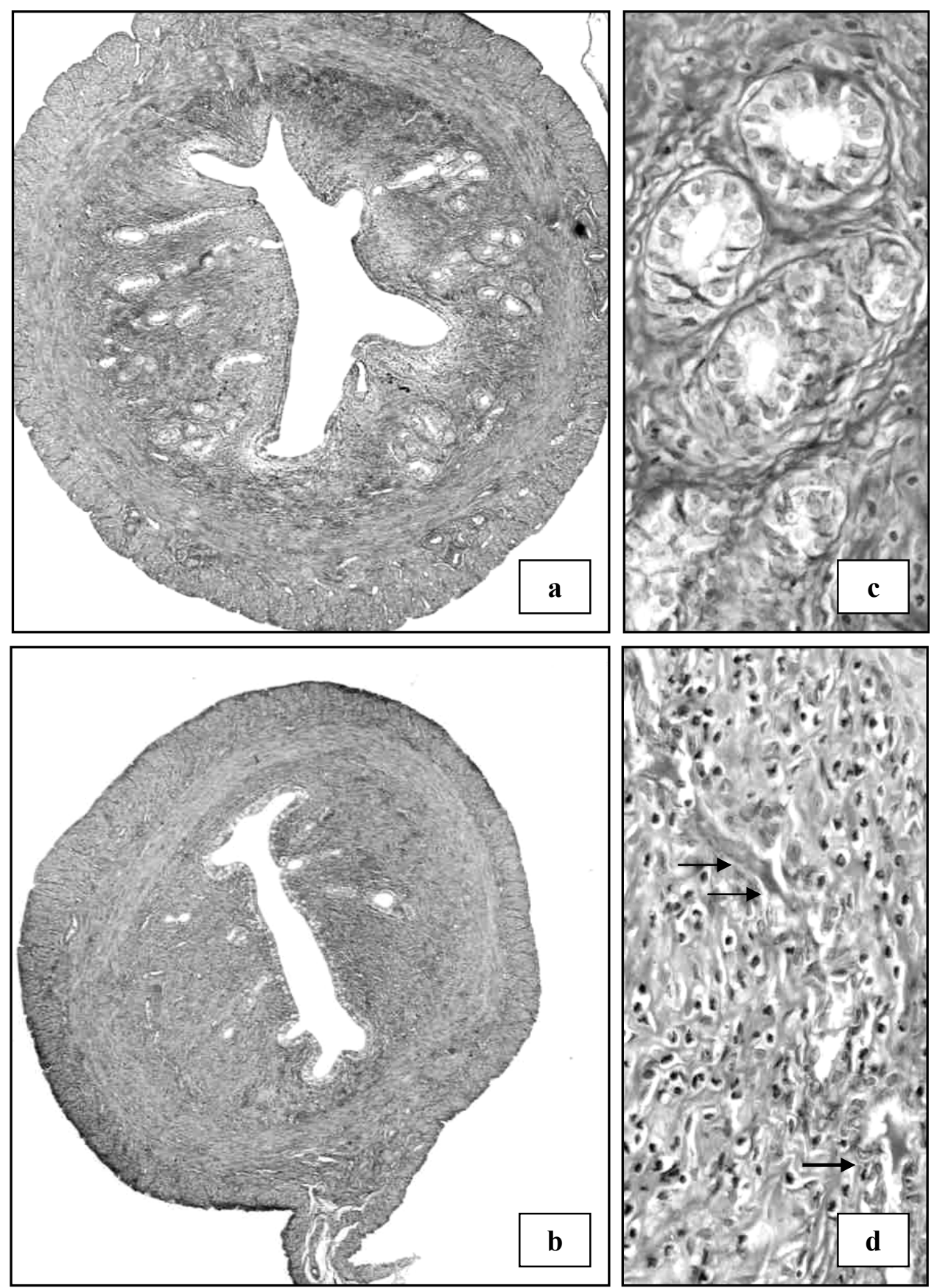

Figura 3. Útero, rata adulta. a) Grupo controle. Parede espessa, PAS, 10,4×. b) Grupo hipotireóideo. Parede delgada. PAS, 10,4×. c) Grupo controle. Glândulas endometriais com células volumosas e com lúmen amplo. PAS, 76×. d) Grupo hipotireóideo. Resquícios das glândulas endometriais apresentando células pequenas em número reduzido e com lúmen estreito (setas). PAS, 76×. 
A atividade secretória da tuba uterina das ratas independente do estado funcional da tireóide obedeceu a mesma seqüência de intensidade, sendo a ampola o segmento com maior secreção, seguida do istmo e do infundíbulo. Esse resultado já foi observado em tubas de ratas adultas normais (Abe, 1996). A intensidade da secreção uterina também não se alterou no hipotireoidismo, apesar da redução significativa do endométrio e do número de glândulas endometriais (Tab. 6). A maioria das ratas eutireóideas e hipotireóideas apresentou secreção uterina de grau 2. $\mathrm{O}$ fato do hipotireoidismo não ter alterado a atividade secretória da tuba e do útero surpreende, já que várias alterações foram observadas no epitélio do infundíbulo e no endométrio. Talvez o método usado para determinar a atividade secretória, não tenha sido o ideal e outras formas de obtenção desses dados devem ser avaliadas a fim de se verificar o efeito do hipotireoidismo na intensidade da secreção tubárica e uterina. Além disso, embora ocorram diferenças na morfologia do útero da rata entre as fases do ciclo estral, o ciclo curto com duração de aproximadamente quatro dias pode limitar a visualização de algumas alterações na histomorfometria do útero e da tuba.

\section{CONCLUSÕES}

O hipotireoidismo induzido por quatro meses em ratas Wistar adultas altera a foliculogênese ovariana e a morfologia tubárica e uterina de ratas em metaestro-diestro. $\mathrm{O}$ hipotireoidismo reduz o número de folículos secundários e terciários, de corpos lúteos e de regiões organizadoras de nucléolo argentafins (AgNORs) nas células da granulosa de folículos secundários, reduz a espessura do endométrio, o número de glândulas endometriais e a altura do epitélio do infundíbulo, mesmo sem alterar a concentração periférica de progesterona e estradiol.

\section{REFERÊNCIAS BIBLIOGRÁFICAS}

ABE, H. The mammalian oviductal epithelium: regional variations in cytological and functional aspects of the oviductal secretory cells. Histol. Histopathol., v.11, p.743-768, 1996.

AUBELE, M.; BIESTERFELD, S.; DERENZINI, M. et al. Guidelines of AgNOR quantitation. Zentralblatt für Pathol., v.140, p.107-108, 1994.

BAKER, S.J.; SPEARS, N. The role of intra-ovarian interactions in the regulation of follicle dominance. Hum. Reprod. Update, v.5, p.153-165, 1999.

BALEN, A.H.; KURTZ, A.B. Successful outcome of pregnancy with severe hypothyroidism. Br. J. Obst. Gynaecol., v.97, p.536-539, 1990.

BRONSON, F.H.; DAGG, C.P.; SNELL, G. Reproduction. In: GREEN, E.L. Biology of the laboratory mouse. 2.ed. New York: Dover Publications, 1975. p.187-204.

CHAN, W.Y.; NG, T.B. Effect of hypothyroidism induced by propylthiouracil and thiourea on male and female reproductive sistems of neonatal mice. J. Exp. Zool., v.273, p.100-169, 1995.

CHUN, S.Y.; HSUEH, A.J.W. Paracrine mechanisms of ovarian follicle apoptosis. J. Reprod. Immunol., v.39, p.63-75, 1998

CROCKER, J.; DAVID, A.R.; EGAN, B. et al. How should we count AgNORs? Proposal for standardized aproach. J. Pathol., v.158, p.185-188, 1989.

DATTA, M.; ROY, P.; BANERJEE, J. et al. Thyroid hormone stimulates progesterone release from human luteal cells by generating a proteinaceous factor. $J$. Endocrinol., v.158, p.319-325, 1998.

DERENZINI, M. The AgNORs. Micron, v.31, p.117120, 2000.

DIJKSTRA, G.; ROOIJ, D.G.; JONG, F.H. et al. Effect of hypothyroidism on ovarian follicular development, granulosa cell proliferation and peripheral hormone levels in the prepubertal rat. Europ. J. Endocrinol., v.134, p.649-654, 1996.

DISSEN, G.A.; DESS, L.; OJEDA, S.R. Neural and neurotrophic control of ovarian development. In: ADASHI, E.Y.; LEUNG, P.C.K. The ovary. New York: Raven, 1993. p.1-19.

ELVIN, A.J.; MATZUK, M.M. Mouse models of ovarian failure. J. Reprod. Fertil., v.3, p.183-195, 1998.

FREEMAN, M.E. The neuroendocrine control of the ovarian cycle of the rat. In: KNOBIL, E.; NEILL J.D. (Eds.). The physiology of reproduction. New York:Raven, 1994. p.613-658.

GHOSH, S.; KABIR, S.; PAKRASCHI, A. et al. A subclinical hypothyroidism: a determinant of polycystic ovary syndrome. Horm. Res., v.39, p.61-66, 1993.

GOUGEON, A.; BUSSO, D. Morphologic and functional determinants of primordial and primary follicles in the monkey ovary. Mol. Cell. Endocrinol., v.163, p.33-41, 2000. 
GREGORASZCZUK, E.L.; KOLODZIEJCZYK, J.; RZYSA, J. Triiodotironine stimulates $3 \quad \beta$ hidroxysteroid dehydrogenase activity in the porcine corpus luteum. Endocrinol. Regul., v.33, p.155-160, 1999.

GREGORASZCZUK, E.L.; SKALKA, M. Thyroid hormone as regulator of basal and human chorionic gonadotrophin-stimulated steroidogenesis by cultured porcine theca and granulosa cells isolated at different stages of the follicular phase. Reprod. Fertil. Dev., v.8, p.961-967, 1996 .

INUWA, I.; WILLIAMS, M.A. Morphometric study on the uterine horn and thyroid gland in hypothyroid, and thyroxine treated hypothyroid rats. J. Anat., v.188, p.383-393, 1996.

JOHNSON, C.H. Reproductive manifestations of thyroid disease. Thyroid disorders, v.24, p.509-515, 1994.

KRASSAS, G.E. Thyroid disease and female reproduction. Fertil. Steril., v.74, p.1063-1070, 2000.

LISON, L. Histochimie al cytochimie animales. Principles et methods. 3.ed. Paris: Gaulthier-Villars, 1960.

MARUO, T.; HAYASHI, M.; HIROYA, M. et al. The role of thyroid hormone as a biological amplifier of the actions of follicle-stimulating hormone in the functional differentiation of cultured porcine granulosa cells. Endocrinology, v.121, p.1233-1241, 1987.

MARUO, T.; KATAYAMA, K.; BARNEA, E.R. et al. A role for thyroid hormone in the induction of ovulation and corpus luteum function. Horm. Res., v.37, p.12-18, 1992a.

MARUO, T.; SHINSUKE, H.; TETSUO, O. Increase in the expression of thyroid hormone receptors in porcine granulosa cells early in follicular maturation. Acta Endocrinol., v.127, p.152-160, 1992b.

MATTHEIJ, J.A.M.; SWARTS, J.J.M.; LOKERSE, P. et al. Effect of hypothyroidism on the pituitarygonadal axis in the adult female rat. Endocrinology, v.146, p.87-94, 1995.

MOWRY, R.W. Alcian Blue technique for the histochemical study of acidic carbohydrates. $J$. Histoch. Cytoch., v.4, p.407, 1956.
OJEDA, S.R.; ROMERO,C.; TAPIA,V. et al. Neurotrophic and cell-cell dependent control of early follicular devolopment. Mol. Cell. Endocrinol., v.163, p.67-71, 2000.

PLOTON, D.; MENAGER, M.; JEANNESSON, P. et al. Improvement in the staining and the visualization of the argyrophilic proteins of nucleolar organizer region at the optical level. Histoch. J., v.18, p.5-14, 1986.

PRIEDKALNS, J. Sistema reprodutor feminino. In: DELLMAN, H.D. Histologia veterinária. Rio de Janeiro: Guanabara Koogan, 1982. p.256-277.

ROSATO, R.R.; GIMENEZ, M.S.; JAHN, G.A. Effects of chronic thyroid hormone administration on pregnancy, lactogenesis and lactation in the rat. Acta Endocrinol., v.127, p.547-554, 1992.

SAMPAIO, I.B.M. Estatística aplicada à experimentação animal. Belo Horizonte: FEP/MVZ, 1998. $211 \mathrm{p}$.

SERAKIDES, R.; NUNES, V.A.; NASCIMENTO, E.F. et al. Foliculogênese e esteroidogênese ovarianas em ratas adultas hipertireóideas. Arq. Bras. Endocrinol. Metabol., v.45, p.258-264, 2001.

SILVA, C.M.; SERAKIDES, R.; NASCIMENTO, E.F. et al. Quantificação das regiões organizadoras de nucléolo (NORs) como parâmetro para avaliar a proliferação das células da granulosa. Arq. Bras. Med. Vet. Zootec., v.55, p.113-116, 2003.

TAMURA, K.; HATSUTA, M.; WATANABE, G. Blockage of gonadotropin-induces first ovulation caused by thyrodectomy and its possible mechanism in rats. Am. J. Physiol., v.275, p. 380-385, 1998.

THOMAS, R.; REID, R.L. Thyroid disease and reproductive dysfunction: A review. Thyroid Reprod., v.70, p.789-798, 1987.

WAKIM, A.; PALJUG, W.R.; JASNOSZ, K.M. et al. Thyroid hormone receptor messenger ribonucleic acid in human granulosa and ovarian stromal cells. Fertil. Steril., v.62, p.531-534, 1994.

WAKIM, A.; POLIZOTTO, S.L.; BUFFO, B.S. et al. Thyroid hormones in human follicular fluid and thyroid hormone receptors in human granulosa cells. Fertil. Steril., v.59, p.1187-1190, 1993. 